Article

\title{
Relationship between Flow Behavior and Microstructure Evolution during Isothermal Compression of near $\beta$ Titanium Alloy Ti-55531 with Acicular Starting Microstructure
}

\author{
Shaojun Li, Yaping Lv, Xiaoyong Zhang * and Kechao Zhou \\ State Key Laboratory of Powder Metallurgy, Central South University, Changsha 410083, China; \\ lishaojun-1986@163.com (S.L.); wslyp525@sohu.com (Y.L.); zhoukechao@csu.edu.cn (K.Z.) \\ * Correspondence: zhangxiaoyong@csu.edu.cn; Tel./Fax: +86-731-8883-0464
}

Received: 22 May 2018; Accepted: 15 June 2018; Published: 19 June 2018

\begin{abstract}
Near $\beta$ titanium alloy Ti-55531 with an acicular starting microstructure was isothermally compressed at $750-825^{\circ} \mathrm{C}$ and $10^{-3}-1 \mathrm{~s}^{-1}$. The microstructure evolution and its influence on the flow behavior of yielding and softening were investigated. Discontinuous or continuous yielding depends on the hindrance to the dislocation motion coming from the $\beta$ grain boundary or $\alpha$ phase. At higher temperatures, the hindrance mainly comes from the $\beta$ grain boundary. Its discontinuous action, including the piling-up and subsequent loosening of dislocations at the $\beta$ grain boundary, leads to discontinuous yielding. At lower temperatures, the continuous hindrance to the dislocation motion, which is exerted by the $\beta$ grain boundary and acicular $\alpha$, causes continuous yielding. Sequentially, the substructures in acicular $\alpha$ are evolved from high-density dislocations or local shear bands, which depend on the orientation relationship between $\beta$ and $\alpha$. Then, the $\beta$ matrix edges into the acicular $\alpha$ along substructure boundaries. The higher strain rate decreases the deformation time to carry out the fragmentation of acicular $\alpha$, while the higher temperature decreases the dislocation density due to the recovery of $\beta$, which does not benefit the substructure formation and subsequent fragmentation of acicular $\alpha$. Therefore, the retardation of acicular fragmentation and the as-resulted decreased flow softening rate are observed.
\end{abstract}

Keywords: near $\beta$ titanium alloy; Ti-55531; hot compression; flow behavior; microstructure evolution

\section{Introduction}

Near $\beta$ titanium alloys such as Ti-55531 (Ti-5Al-5Mo-5V-3Cr-1Zr) have a good combination of strength, fracture toughness, and fatigue resistance, which are extensively used as a kind of high-performance aerospace structural material [1-4]. The mechanical properties of these alloys show a strong dependence on microstructure. Therefore, hot deformation has attracted much attention because of its importance to the microstructure control. For example, hot deformation has a great effect on the fragmentation of acicular $\alpha$ into equiaxial morphology. As a result, the plasticity (governed by equiaxial $\alpha$ ) and fracture toughness (governed by acicular $\alpha$ ) can be controlled effectively [5-7]. Yielding and softening are the important plastic flow behaviors during hot deformation: yielding is related to the initiation of softening after overcoming the maximum deformation resistance, while softening determines the microstructure control. Therefore, it is necessary to understand the relationship between flow behaviors and microstructure evolution.

Yielding can be continuous or discontinuous, as explained by the static or dynamic theories. The static theory attributes discontinuous yielding to: (1) the pinning of dislocations by large solute atoms or impurities (upper yielding point), followed by (2) the continuous dislocation motion after 
mobilizing from pinning points (lower yielding point) [8]. Some near $\alpha$ Ti-alloys such as IMI834 show discontinuous yielding at a high strain rate and temperature (above the $\beta$-transus point), which has been explained as the initial pinning of dislocations by the large alloyed atoms with high content of alloy elements [9]. The dynamic theory explains discontinuous yielding as the rapid increase of mobile dislocations, leading to a drop in stress from the upper yield point to the lower yield point. Two related increasing patterns are: (1) the rapid generation of mobile dislocations at the grain boundary (as a dislocation source), and (2) the unpinning process of pinned dislocations at the $\beta$ grain boundary (as a motion hindrance) [10]. Both patterns have been observed in Ti-alloys. Philippart et al. [11] found that the discontinuous yielding of metastable $\beta$ alloy Ti-6.8Mo-4.5Fe-1.5Al could be related to the grain boundary-associated dislocation generation. Furthermore, the higher discontinuous yielding degree at a higher strain rate can be related to the more rapid dislocation generation at the grain boundary. Lai et al. [12] observed the dislocations piling up at the $\beta$ boundary and then entering into the adjacent the $\beta$ grain in Ti-17, which supports the second pattern to cause discontinuous yielding.

As for softening after yielding, this mechanism is mainly based on the dynamic $\beta$ recovery and $\alpha$ recrystallization. The resultant important phenomena include the substructure formation and sequential fragmentation in acicular $\alpha$, which are closely related to the dislocation motion, especially the slip transmission at the $\alpha / \beta$ interface. It has been reported that the slip transmission of dislocations is greatly influenced by the $\alpha / \beta$ orientation relationship. For example, slip transmission is easier to proceed with the Burgers orientation relationship (BOR) of $(110)_{\beta} \|(0001)_{\alpha}$ and $[1 \overline{1} 1]_{\beta} \|[11 \overline{2} 0]_{\alpha}$. Castany et al. [13] reported that, during the deformation of duplex-microstructural Ti-6Al-4V, the interface between the secondary $\alpha$ and $\beta$ with BOR does not hinder the dislocation motion, while that with no BOR blocks the dislocation motion. Suri et al. [14] investigated the slip transmission at different orientations and planes in near $\alpha$ Ti-alloy Ti-5Al-2.5Sn-0.5Fe. Within the slip systems of $(0001)_{\alpha} /[11 \overline{2} 0]_{\alpha}$ and $(110)_{\beta} /[1 \overline{1} 1]_{\beta}$, when two specific slip orientations were parallel each other, the dislocations were easy to pass through the $\alpha / \beta$ interface via slip transmission; otherwise, the dislocations have to pile up at the $\alpha / \beta$ interface. The above influence of the $\alpha / \beta$ orientation relationship on slip transmission was also confirmed in commercial-purity titanium and Ti-6Al-4V [15], which would undoubtedly influence the further dislocation evolution and substructure formation. For example, it was found that the dislocation-evolution-related $\alpha$ recrystallization is the main pattern of substructure formation [16]. However, Weiss et al. [17] reported another formation phenomenon via local shear bands during the deformation of Ti-6Al-4V at $955^{\circ} \mathrm{C}$ and a constant crosshead speed of $2 \times 10^{-4} \mathrm{~m} / \mathrm{s}$, although no more details were given. Sequentially, acicular $\alpha$ is fragmented gradually by the edging of the $\beta$ matrix along the interface between substructures, in which the driving force is considered to be the discrepancy of tension between $\alpha / \alpha$ and $\alpha / \beta$ interfaces [18].

The above investigations mainly focus on near $\alpha$ and $\alpha+\beta$ Ti-alloys. Their most investigated microstructure is the Widmannstatten structure, showing the lamellar $\alpha$ and $\beta$ with alternating arrangement [13], which is different from near $\beta$ Ti-alloys, which show well-precipitated acicular $\alpha$ in $\beta$ grains. Firstly, since different Ti-alloys may have their own patterns to cause continuous or discontinuous yielding as mentioned above, the pattern considering the microstructure feature of near $\beta$ Ti-alloys needs to be revealed. Furthermore, in the Widmannstatten structure, the BOR between neighboring acicular $\alpha$ and $\beta$ can be maintained before the fragmentation of acicular $\alpha$, which suggests the benefit for the slip transmission of dislocations at the $\alpha / \beta$ interface. However, during the deformation of near $\beta$ Ti-alloys, the acicular $\alpha$ are easy to move, rotate, or bend at the action of the plastic flow of the $\beta$ matrix. This suggests that the orientation relationship between $\alpha$ and $\beta$ is mutable, leading to complexity in the slip transmission at the $\alpha / \beta$ interface. The influence of this complexity on the substructure formation pattern has seldom been reported.

In this study, near $\beta$ Ti-alloy Ti-55531 with an acicular starting microstructure was isothermally compressed at $750-825^{\circ} \mathrm{C}$ with a strain rate of $10^{-3}-1 \mathrm{~s}^{-1}$. The continuous or discontinuous yielding at different deformation conditions was investigated. The dislocation evolution at different orientation 
relationships between neighboring $\alpha$ and $\beta$ phases, as well as its influence on the following substructure formation and fragmentation in the acicular $\alpha$, were analyzed.

\section{Experimental Details}

\subsection{Material}

A $\varphi$ 200-mm Ti-55531 billet (Hunan Goldsky Titanium Industry Technology Co., Ltd., Changsha, China) was used as the starting material. Table 1 lists its alloyed composition detected by PS-6 inductively coupled plasma. The $\beta$-transus temperature $\left(\mathrm{T}_{\beta}\right)$ was approximately $825 \pm 5{ }^{\circ} \mathrm{C}$, measured by a metallographic method. The billet was solution-heated at $880{ }^{\circ} \mathrm{C}$ for $15 \mathrm{~min}$, water-quenched to room temperature, and then aged at $600{ }^{\circ} \mathrm{C}$ for $120 \mathrm{~min}$, followed by a final water-quenching to room temperature.

Table 1. Alloy composition of the received Ti-55531.

\begin{tabular}{cccccccc}
\hline Element & Al & Mo & V & Cr & Zr & Fe & Impurity Elements \\
\hline wt \% & 5.20 & 4.92 & 4.96 & 2.99 & 1.08 & 0.40 & 0.16 \\
\hline
\end{tabular}

\subsection{Isothermal Compression}

Isothermal compression was conducted on a Gleeble-3500 simulator. Several cylindrical samples were line cut from the heat-treated billet and then mechanically polished into $\varphi 8 \times 12 \mathrm{~mm}$. A $\varphi$ 0.8-mm hole was drilled at the mid-height side of the samples, and a K-type thermocouple was inserted and welded in this hole to monitor the temperature. Graphite foils were placed between samples and machine platens for lubrication. Samples were resistance-heated to the pre-set temperature $\left(750,775,800\right.$, and $825^{\circ} \mathrm{C}$ in this study) at a heating rate of $10^{\circ} \mathrm{C} / \mathrm{s}$, soaked for $2 \mathrm{~min}$ to ensure temperature uniformity, and then compressed to the true strain of 0.7 at the strain rate of $10^{-3}, 10^{-2}$, $10^{-1}$, and $1 \mathrm{~s}^{-1}$. Additionally, other samples were isothermally compressed to the intermediate strain at some specific conditions to investigate the microstructure evolution. After compressing to the set strain, the specimen was cooled by an argon gas-jet at a cooling rate of about $50{ }^{\circ} \mathrm{C} / \mathrm{s}$ to retain the in situ deformed microstructure for the subsequent micro-observation.

\subsection{Metallography and Analysis}

The compressed samples were cut along the center axis of compression. The cut faces were mechanically polished and etched with Kroll's reagent $\left(3 \mathrm{~mL} \mathrm{HNO}_{3}+1.5 \mathrm{~mL} \mathrm{HF}+100 \mathrm{~mL} \mathrm{H}_{2} \mathrm{O}\right)$. The microstructures were observed on a NOVA Nano SEM 230 (FEI Electron Optics B.V., Brno, Czech Republic) scanning electron microscope (SEM). Further microstructural observation was performed on a JEOL JEM-2100F (JEOL Ltd., Tokyo, Japan) transmission electron microscope (TEM). The thin foils for TEM observation were prepared by mechanically thinning to $100 \mu \mathrm{m}$, and then electrolytically thinning on a twin jet polisher with the electrolytic solution of $600 \mathrm{~mL}$ methanol + $350 \mathrm{~mL}$ butanol $+50 \mathrm{~mL}$ perchloric acid at $-30{ }^{\circ} \mathrm{C}$ and a voltage of $23 \mathrm{~V}$.

\section{Results}

\subsection{Heat-Treated Microstructure}

Figure 1 shows the backscattered electron micrographs of the heat-treated Ti-55531. $\beta$ matrix grains $(200-350 \mu \mathrm{m})$ were separated by $\alpha$ layers at the $\beta$ grain boundaries (Figure 1a). The acicular $\alpha$ with a length of $2.1-4.5 \mu \mathrm{m}$ and a width of $0.2-0.5 \mu \mathrm{m}$, which obeyed the triangle Burgers orientation relationship, precipitated in the $\beta$ grains homogeneously (Figure 1b). The volume fraction of the $\alpha$ phase was about $37.4 \mathrm{vol} \%$, measured by photo pixels counting based on Image Pro Plus 6.0. 

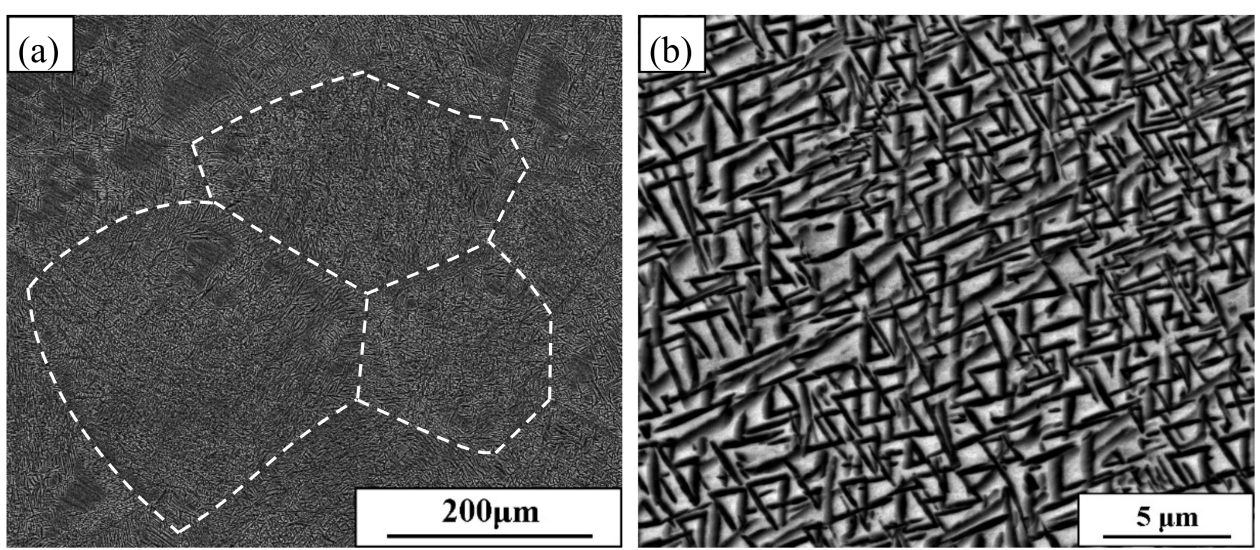

Figure 1. SEM micrograph of the heat-treated Ti-55531.

\subsection{Flow Behavior}

Figure 2 shows the curves of strain $\varepsilon$ versus stress $\sigma$ at $750-825^{\circ} \mathrm{C}$ and a strain rate of $10^{-3}-1$ $\mathrm{s}^{-1}$. In general, the stress decreased with the increase of temperature and the decrease of strain rate. Continuous or discontinuous yielding could be observed at the beginning of deformation. At the relatively low temperature and strain rate, the continuous yielding only displayed a continuous flow softening after the peak stress. With the increasing of temperature and strain rate, the discontinuous yielding, which showed a lower yielding point after the peak stress (the upper yielding point), became obvious. After yielding, Figure 3 shows the relationship of the flow softening rate $-\mathrm{d} \sigma / \mathrm{d} \varepsilon$ versus strain $\varepsilon$ at the continuous flow softening stage. With the increase of strain $\varepsilon$, the $-\mathrm{d} \sigma / \mathrm{d} \varepsilon$ value increased first and then decreased. Furthermore, Figure 4 shows the relationship between the critical strain $\varepsilon_{\mathrm{m}}$ corresponding to the maximum of $-\mathrm{d} \sigma / \mathrm{d} \varepsilon$ and the deformation conditions. It can be seen that $\varepsilon_{\mathrm{m}}$ increased with the increase of temperature and strain rate. Both Figures 3 and 4 confirm the decreasing the flow softening rate at higher strain temperatures and strain rates. Continuous or discontinuous yielding at the beginning of deformation and the following regulation of continuous flow softening would be related to the microstructure evolution at different deformation conditions.
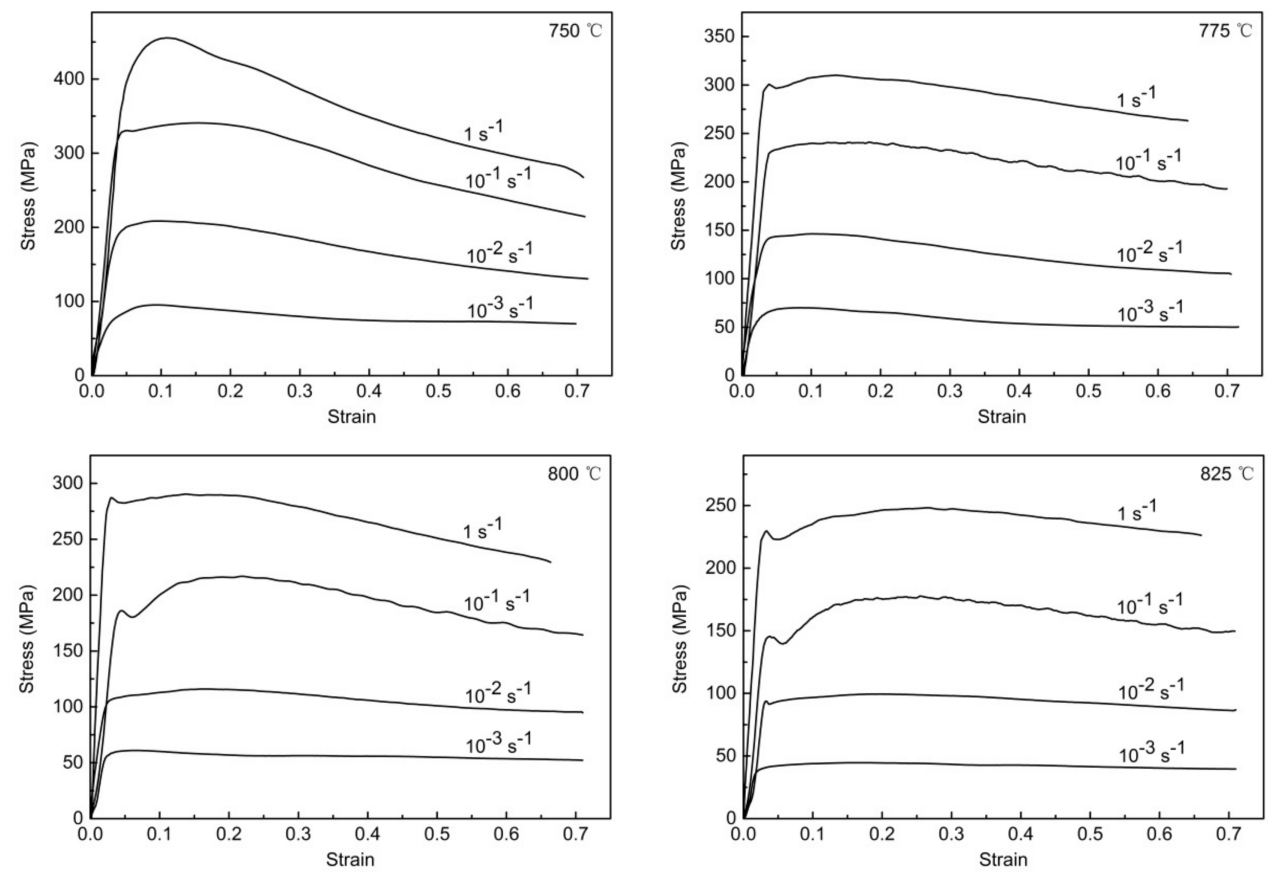

Figure 2. Curves of stress $\sigma$ versus strain $\varepsilon$ at $750-825^{\circ} \mathrm{C}$ and $10^{-3}-1 \mathrm{~s}^{-1}$. 

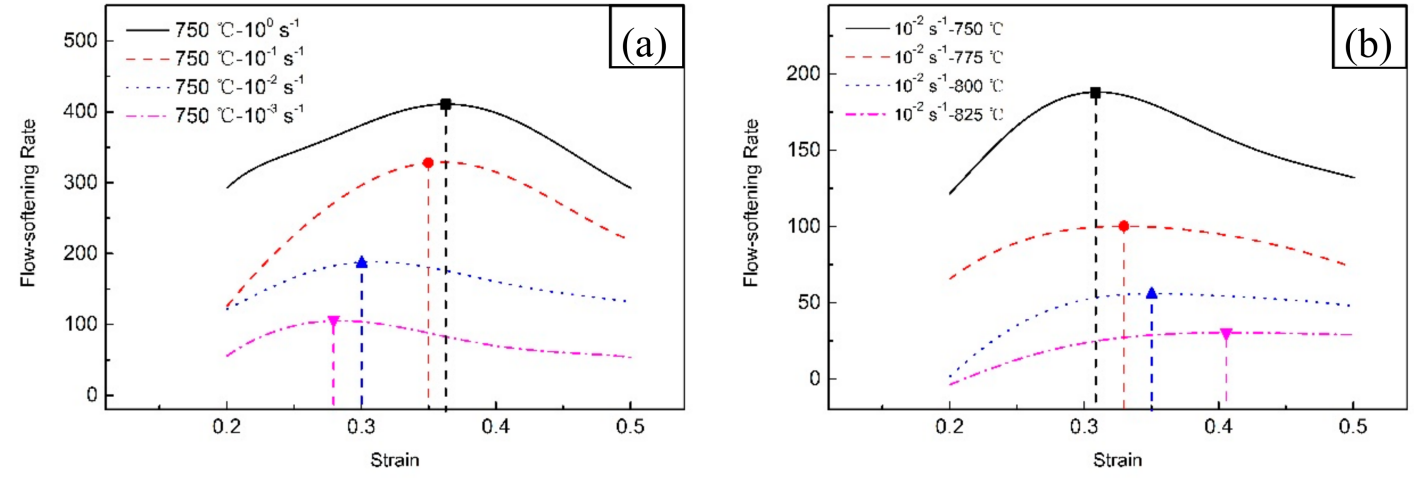

Figure 3. Relationship of the flow softening rate $-\mathrm{d} \sigma / \mathrm{d} \varepsilon$ versus strain $\varepsilon$ at $750-825^{\circ} \mathrm{C}$ and $10^{-3}-1 \mathrm{~s}^{-1}$.

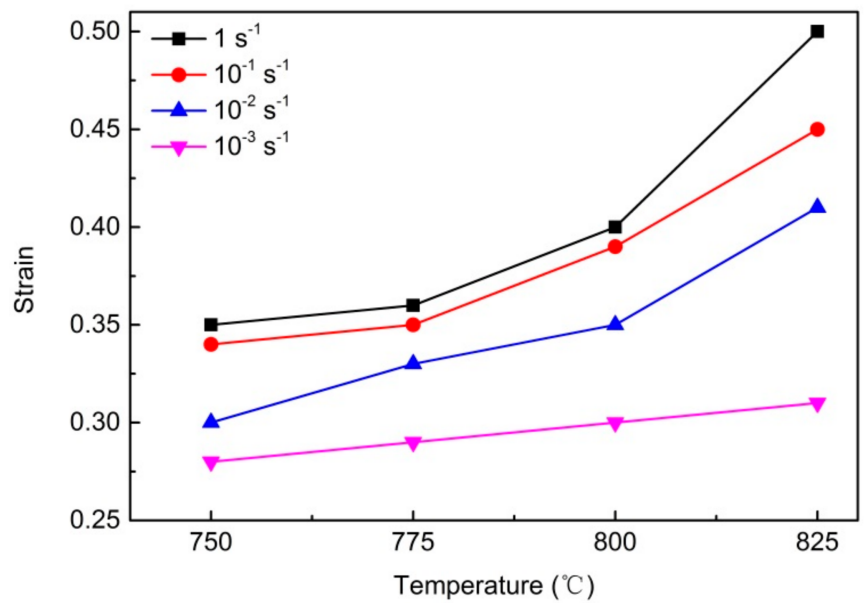

Figure 4. Relationship between the $\varepsilon_{\mathrm{m}}$ corresponding to the maximum of $-\mathrm{d} \sigma / \mathrm{d} \varepsilon$ and the deformation conditions.

\subsection{Microstructure Characterization}

\subsubsection{Continuous/Discontinuous Yielding}

Figures 5 and 6 show the microstructures compressed to the peak stress at $825{ }^{\circ} \mathrm{C} / 1 \mathrm{~s} \mathrm{~s}^{-1}$ (discontinuous yielding) and $750{ }^{\circ} \mathrm{C} / 10^{-3} \mathrm{~s}^{-1}$ (continuous yielding), respectively. Then, the microscopic mechanism of yielding can be related to the hindrance to dislocation motion, while the hindrance mainly comes from the $\beta$ grain boundary and $\alpha$ phase as the pinning points. At a high deformation temperature, the $\alpha$ phase content was very low, for example, only about $3.0 \mathrm{vol} \%$ at $825{ }^{\circ} \mathrm{C}$ (Figure 5a). Therefore, the $\beta$ grain boundary is the main hindrance to dislocation motion. It is noted that the uniform hindrance coming from the flat $\beta$ grain boundary leads to the parallel distribution of piled-up dislocations near the $\beta$ grain boundary (Figure $5 b$ ). The mechanism of a sudden increase in the mobile dislocation density is: (1) the piling-up of dislocations at the $\beta$ grain boundary, which causes a high deformation resistance up to the peak stress (the upper yielding point), and then (2) the unpinning process of pinned dislocations at the $\beta$ grain boundary and their entrance into the neighbor $\beta$ grain, which suggests the increase of mobile dislocations and then causes a drop in stress (the lower yielding point). As a result, discontinuous yielding appears. Since the higher strain rate raises the piling-up degree of dislocations and then triggers the higher peak stress [19], a larger discrepancy between the upper and lower yielding points can be observed, as shown in Figure 2. 

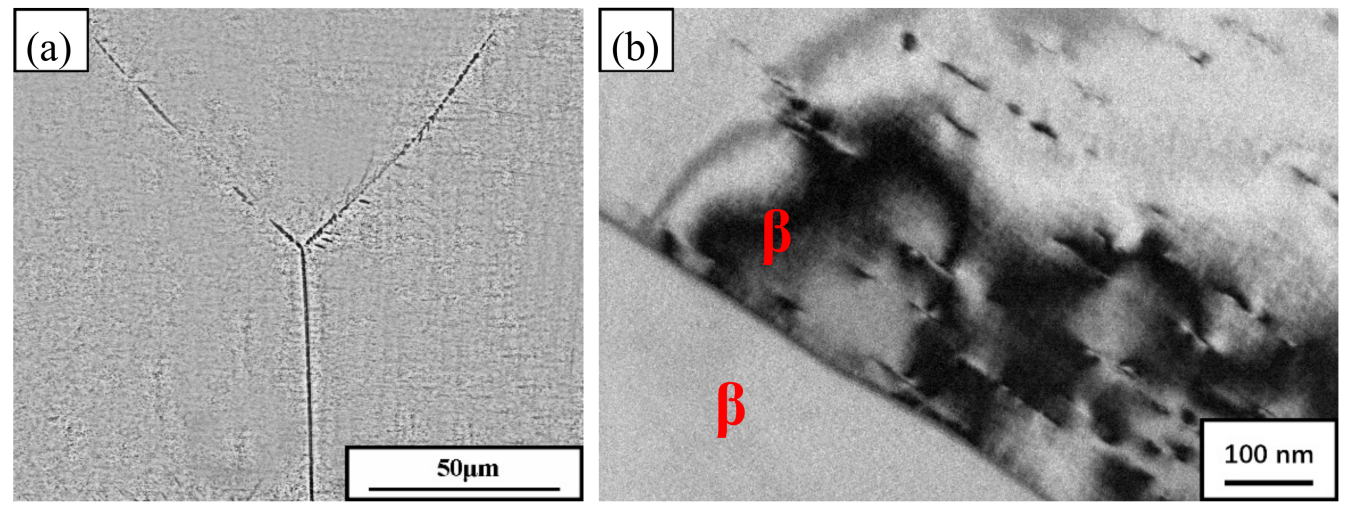

Figure 5. Microstructures of Ti-55531 after compressing to the peak stress at $825{ }^{\circ} \mathrm{C} / 1 \mathrm{~s}^{-1}$ (discontinuous yielding).

By decreasing the temperature from $825^{\circ} \mathrm{C}$ to $750{ }^{\circ} \mathrm{C}$, the $\alpha$ phase content was increased to about $30.0 \mathrm{vol} \%$ (Figure $6 \mathrm{a}$ ). Therefore, the effect of the $\alpha$ phase on the dislocation motion must be considered: even after breaking the hindrance of the $\beta$ grain boundary and then entering into the neighboring $\beta$ grain, dislocation motion is still continuously blocked by the $\alpha$ phase dispersing homogeneously into the $\beta$ grain. The continuous hindrance by the $\beta$ grain boundary and $\alpha$ phase together suggests the weak mutation of the amount of mobile dislocations, which manifests as continuous yielding.
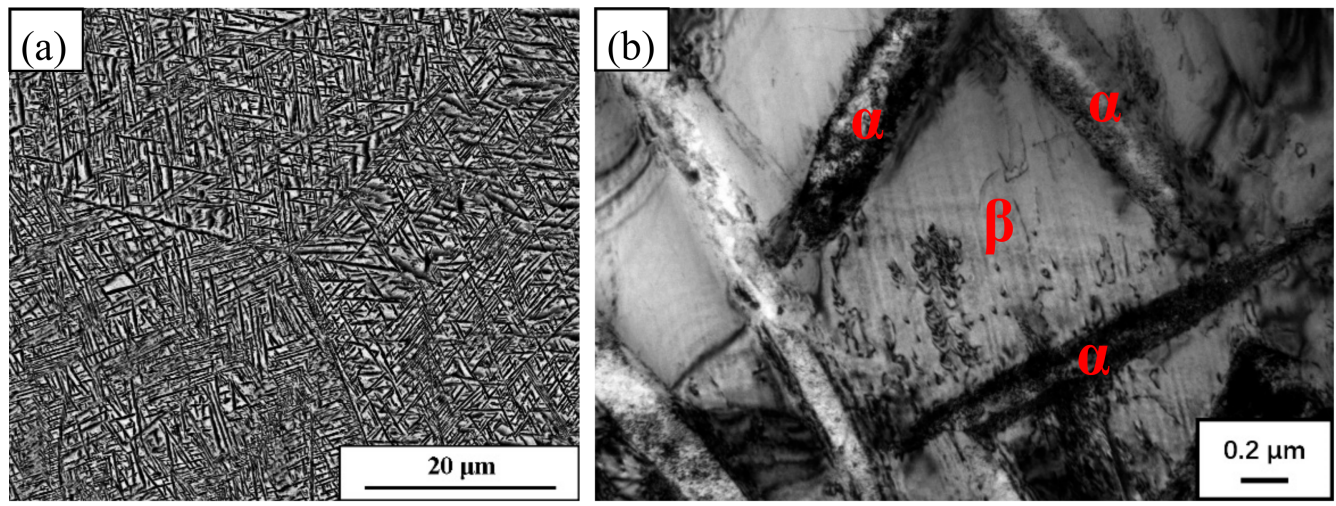

Figure 6. Microstructure of Ti-55531 after compressing to the peak stress at $750{ }^{\circ} \mathrm{C} / 10^{-3} \mathrm{~s}^{-1}$ (continuous yielding).

\subsubsection{Fragmentation of Acicular $\alpha$}

Figure 7 shows the SEM graphs depicting the evolution of the acicular $\alpha$ during compression at $750{ }^{\circ} \mathrm{C} / 10^{-3} \mathrm{~s}^{-1}$, in which the arrow shows the loading direction. At the strain of 0.1 (Figure $7 \mathrm{a}$ ), the majority of $\alpha$ particles still retain an acicular morphology. However, the initial triangle orientation among acicular $\alpha$ was destroyed. Under the action of the plastic flow of the $\beta$ matrix along the radial direction of the cylindrical specimen, the acicular $\alpha$ tend to be perpendicular to the loading direction. Additionally, some acicular $\alpha$ initially perpendicular to the loading direction were fragmented into several parts. By increasing the strain to 0.4 (Figure $7 \mathrm{~b}$ ), the majority of acicular $\alpha$ particles are fragmented into a small aspect ratio. At the strain of 0.7 (Figure 7c), the acicular $\alpha$ were completely transformed into an equiaxed morphology with an average size of $0.4 \mu \mathrm{m}$. 

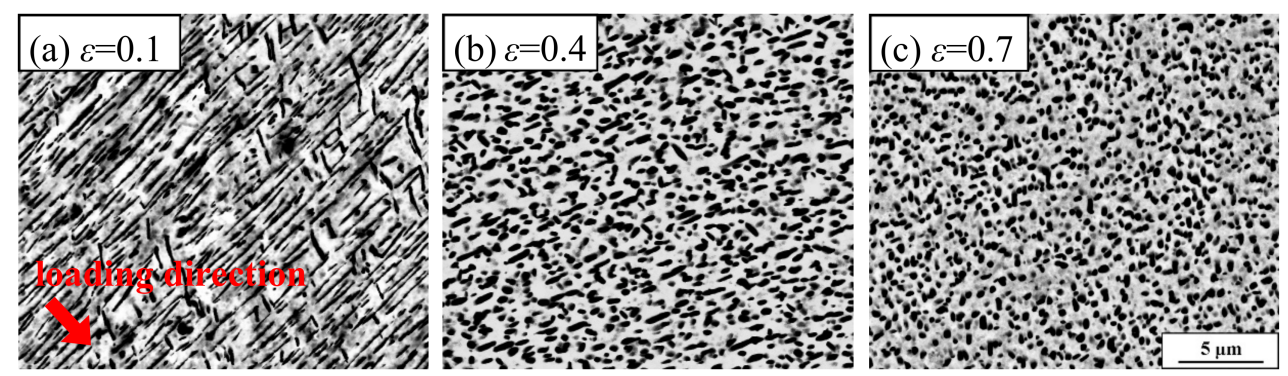

Figure 7. Microstructures of Ti-55531 after a compressive strain of (a) 0.1 ; (b) 0.4 ; and (c) 0.7 at $750{ }^{\circ} \mathrm{C} / 10^{-3} \mathrm{~s}^{-1}$.

Figure 8 shows the TEM graphs compressed at $750{ }^{\circ} \mathrm{C} / 10^{-3} \mathrm{~s}^{-1}$ to the strain of 0.1 (Figure $8 \mathrm{a}, \mathrm{b}$ ) and 0.4 (Figure $8 \mathrm{c}$ ), in which the selected area electron diffraction confirms the Burgers orientation relationship between the neighboring $\beta$ and $\alpha$ phases: $(110)_{\beta} \|(0001)_{\alpha}$ and $[1 \overline{1} 1]_{\beta} \|[11 \overline{2} 0]_{\alpha}$. In this situation, the dislocation configuration at the $\alpha / \beta$ interface (arrow in Figure 8a) shows the slip transmission of dislocations from the $\beta$ matrix into acicular $\alpha$ at the strain of 0.1. As a result, the dislocation density in acicular $\alpha$ increases accordingly, which benefits the following substructure formation. At the strain of 0.4 (Figure $8 b$ ), substructure boundaries appear in acicular $\alpha$, while some recovery characteristics, such as dislocation network and subgrain boundaries, can also be found in the $\beta$ matrix. Figure $8 \mathrm{c}$ shows the edging of $\beta$ into acicular $\alpha$ along substructure boundaries $(\alpha \rightarrow \beta$ transformation), leading to the formation of indentations in the long sides of acicular $\alpha$, followed by the deepening of indentations and then the fragmentation of acicular $\alpha$. The driving force for the deepening of indentations comes from the discrepancy of tension between the $\alpha / \alpha$ and $\alpha / \beta$ interfaces. This drives the diffusion of alloyed elements at the joint of the $\alpha / \alpha$ and $\alpha / \beta$ interfaces. As a result, the diffusional transformation of $\alpha \rightarrow \beta$ at the joint is promoted, which causes the deepening of indentations by replacing the $\alpha$ region with the $\beta$ region in the long sides of acicular $\alpha$.
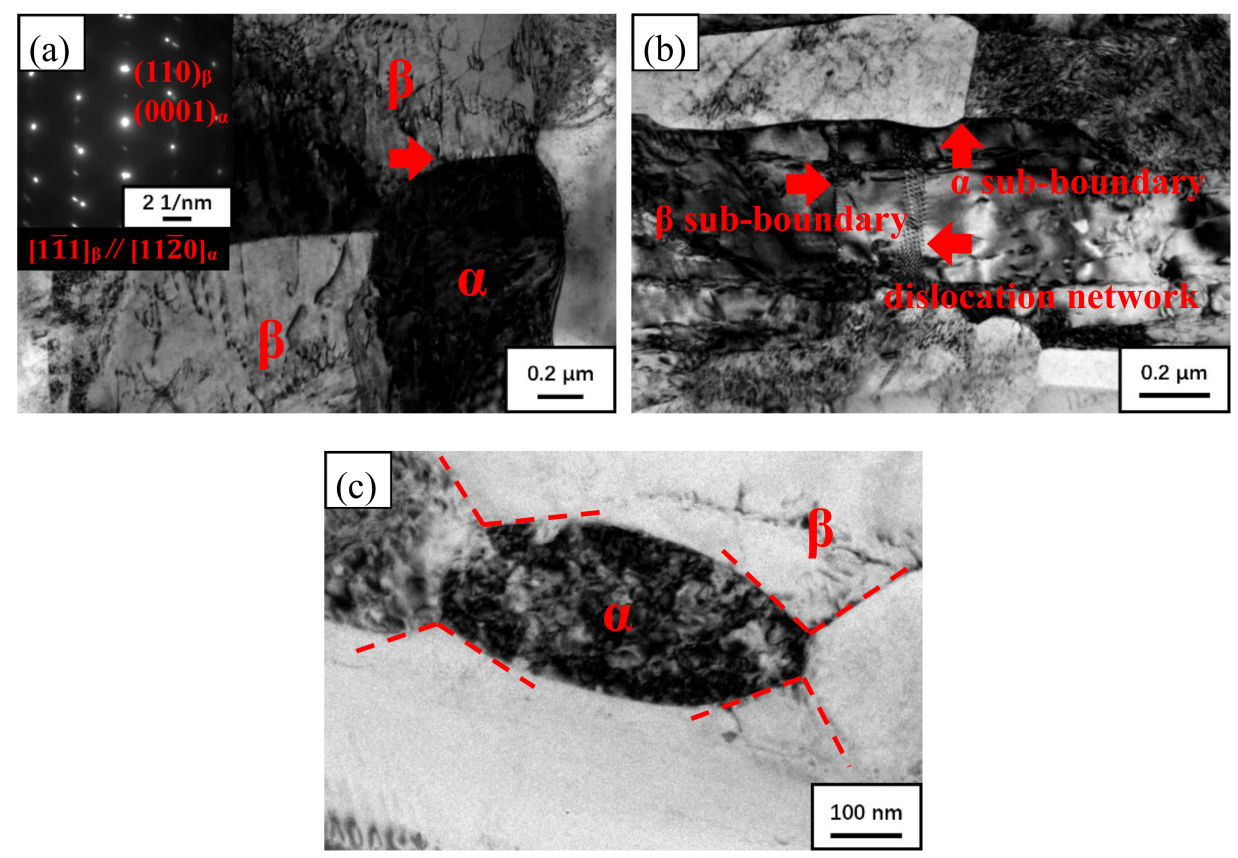

Figure 8. TEM graphs of microstructure evolution with the Burgers orientation relationship between the neighboring $\beta$ and $\alpha$; (a) slip transmission of dislocations at the $\alpha / \beta$ interface at the strain of 0.1 , (b) formation of substructure in $\alpha$ and $\beta$ at the strain of 0.4 , and (c) hedging of the $\beta$ phase into the acicular $\alpha$ phase along the $\alpha / \alpha$ interface. 
When there is no Burgers orientation relationship between the neighboring $\alpha$ and $\beta$, as shown in Figure 9 (TEM graphs compressed at $750{ }^{\circ} \mathrm{C} / 10^{-3} \mathrm{~s}^{-1}$ to the strain of 0.1 (Figure $9 \mathrm{a}, \mathrm{b}$ ) and 0.4 (Figure 9c)), a high piling-up of dislocations at the $\alpha / \beta$ interface can be found at the strain of 0.1 (Figure 9a). This suggests that, because of the large orientation mismatch between the neighboring $\beta$ and $\alpha$, the dislocation motion ends at the $\alpha / \beta$ interface instead of proceeding from the $\beta$ matrix into acicular $\alpha$ via slip transmission. The dislocation piling-up triggers the stress concentration at the $\alpha / \beta$ interface, and then further leads to the formation of local shear bands in acicular $\alpha$ (Figure 9b). A similar result was also reported in the hot deformation of Ti-6Al-4V with a colony- $\alpha$ microstructure at $600{ }^{\circ} \mathrm{C} / 10^{-3} \mathrm{~s}^{-1}$ [20]. Sequentially, the $\beta$ matrix edges into acicular $\alpha$ along the interface between shear bands through $\alpha \rightarrow \beta$ transformation at the strain of 0.4 (Figure $9 \mathrm{c}$ ), which results in the gradual fragmentation of acicular $\alpha$. It can be deduced that, since the piled-up dislocations at the $\alpha / \beta$ interface can serve as more channels for the diffusion of alloyed elements, which has been confirmed in another Ti-alloys such as Ti-6Al-4V [17,21], the diffusional transformation of $\alpha \rightarrow \beta$ and the resultant edging of the $\beta$ matrix into acicular $\alpha$ can be further promoted.
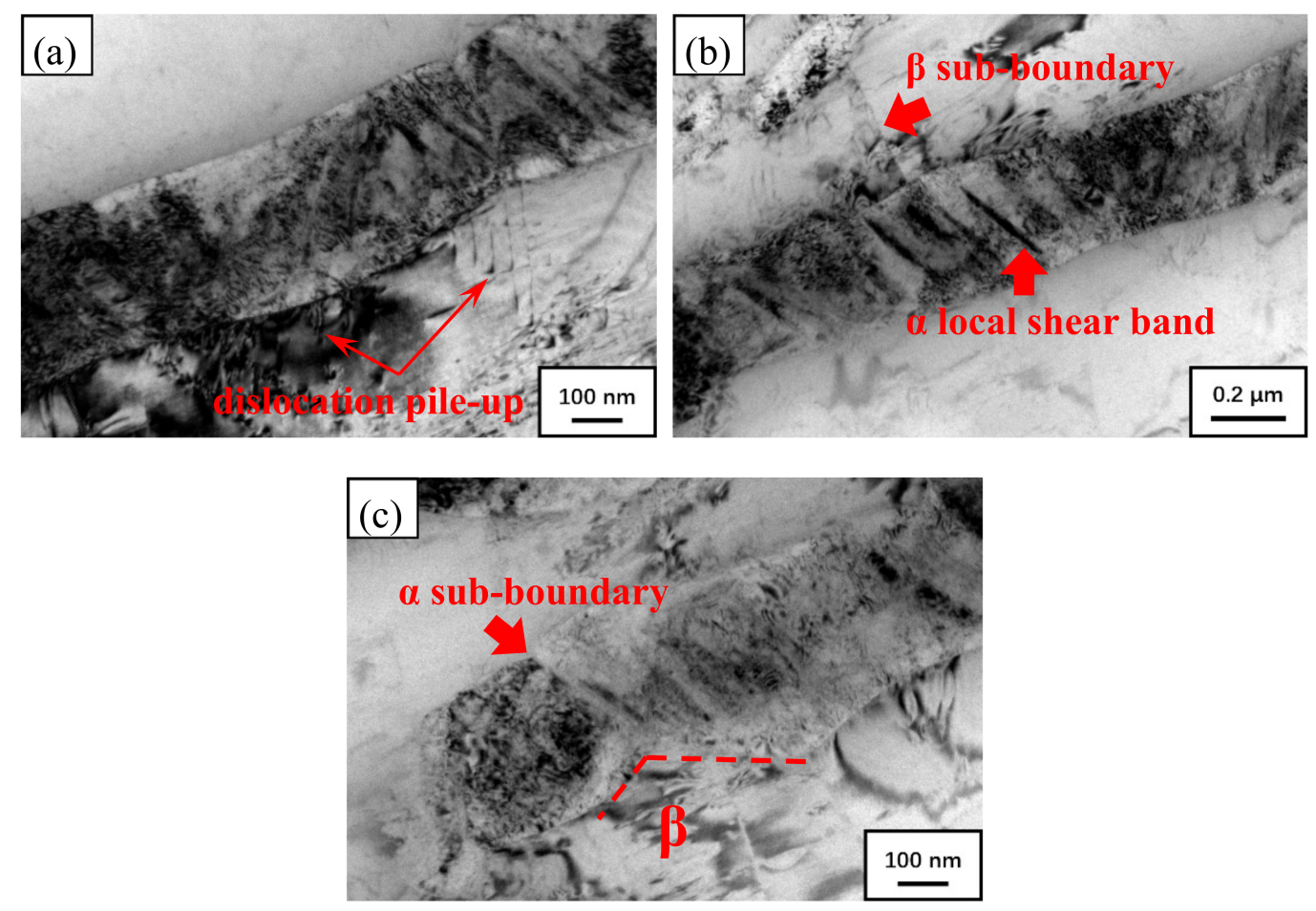

Figure 9. TEM graphs of microstructure evolution without the Burgers orientation relationship between the neighboring $\beta$ and $\alpha$ : (a) piling-up of dislocations at the $\alpha / \beta$ interface at the strain of 0.1 ; (b) formation of local shear bands in acicular $\alpha$ at the strain of 0.4 ; and (c) hedging of the $\beta$ phase into the acicular $\alpha$ phase along the interface among shear bands.

Figure 10 shows the influence of temperature and strain rate on the evolution of acicular $\alpha$. By increasing the strain rate from $10^{-3} \mathrm{~s}^{-1}$ (Figure 7) to $10^{-1} \mathrm{~s}^{-1}$ (Figure 10a-c) at $750{ }^{\circ} \mathrm{C}$, the deformation time is too short to carry out the fragmentation of acicular $\alpha$. Therefore, after compressing to the strain of 0.4 at $10^{-1} \mathrm{~s}^{-1}$ (Figure 10b), many acicular $\alpha$ with the aspect ratio of 2.6 6.1 still remain. By increasing the temperature from $750{ }^{\circ} \mathrm{C}$ to $775{ }^{\circ} \mathrm{C}$ at $10^{-3} \mathrm{~s}^{-1}$ (Figure $10 \mathrm{~d}-\mathrm{f}$ ), its obvious effects are the decrease of $\alpha$ content and the coarsening of the $\alpha$ phase because of the faster Ostwald ripening. For example, at the strain of 0.1 , the $\alpha$ content is decreased to $23.5 \mathrm{vol} \%$ at $775{ }^{\circ} \mathrm{C}$ (Figure $10 \mathrm{~d}$ ) compared with 30.0 vol \% at $750{ }^{\circ} \mathrm{C}$ (Figure 7a). Also, the $\alpha$ phase coarsens to $0.5 \mu \mathrm{m}$ in the average acicular width at the strain of 0.4 (Figure 10e) and then $0.9 \mu \mathrm{m}$ in the average equiaxed diameter at the strain of 0.7 (Figure 10f). Additionally, increasing the temperature also retards the fragmentation of acicular $\alpha$ : many acicular $\alpha$ 
with the aspect ratio of $2.3 \sim 4.7$ can be observed at $775^{\circ} \mathrm{C}$ and the strain of 0.4 (Figure 10e). As shown in Figures 8 and 9, no matter what kind of substructure formation in acicular $\alpha$, the $\beta$ matrix always shows some recovery characteristics, which suggests the decrease of the dislocation density in the $\beta$ matrix. Furthermore, increasing the temperature can promote $\beta$ recovery, and then further decrease the dislocation density. As a result, in case of BOR between the neighboring $\alpha$ and $\beta$, the amount of dislocations entering into acicular $\alpha$ via slip transmission decreases, which does not benefit the formation of dislocation evolution-related substructure in acicular $\alpha$; in the case of no BOR between the neighboring $\alpha$ and $\beta$, the dislocation piling-up and resultant stress concentration at the $\alpha / \beta$ interface become weak, which does not benefit the formation of shear band-related substructure in acicular $\alpha$. Because the substructure formation is necessary before the fragmentation of acicular $\alpha$, the increased difficulty of substructure formation at higher temperatures also retards the fragmentation of acicular $\alpha$. A similar phenomenon and regulation have also been found during the deformation of near $\beta$ Ti-alloy Ti-55511 at different temperatures [22]. In addition, it was reported that the fragmentation of acicular $\alpha$ has the great contribution to the flow softening degree [23]. Therefore, since a higher strain rate and temperature retard the fragmentation of acicular $\alpha$ as mentioned above, the flow softening is also retarded, which leads to the increase of the critical strain $\varepsilon_{\mathrm{m}}$ corresponding to the maximum flow softening rate $-\mathrm{d} \sigma / \mathrm{d} \varepsilon$, as shown in Figure 4.
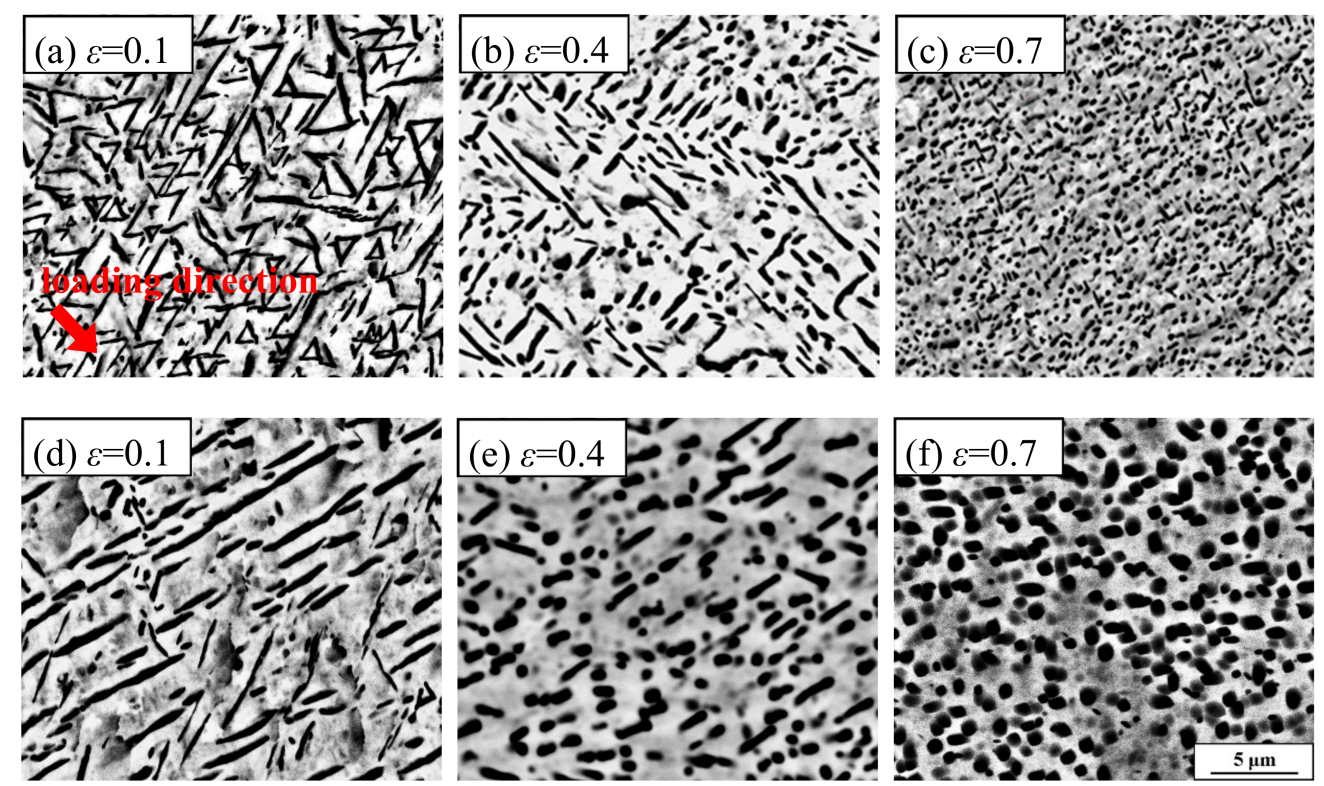

Figure 10. Micrograph of Ti-55531 after compressing at $750{ }^{\circ} \mathrm{C} / 10^{-1} \mathrm{~s}^{-1}(\mathbf{a}-\mathbf{c})$ and $775{ }^{\circ} \mathrm{C} / 10^{-3} \mathrm{~s}^{-1}$ (d-f) to the strain of $0.1,0.4$, and 0.7 , respectively.

\section{Conclusions}

(1) In general, the flow behavior of Ti-55531 with an acicular starting microstructure includes a yielding and a subsequent softening during compression at $750-825{ }^{\circ} \mathrm{C}$ with a strain rate of $10^{-3}-1 \mathrm{~s}^{-1}$. Furthermore, the stress decreases with the increase of the temperature and the decrease of the strain rate.

(2) Discontinuous or continuous yielding can be related to the hindrance to the dislocation motion caused by the $\beta$ grain boundary or $\alpha$ phase at different deformation conditions. At higher temperatures, due to the low $\alpha$ content, the hindrance mainly comes from the $\beta$ grain boundary. Its discontinuous action including the piling-up and then unpinning of dislocations at the $\beta$ grain boundary, which leads to discontinuous yielding. At lower temperatures, continuous yielding appears by the continuous hindrance to dislocation motion exerted by the $\beta$ grain boundary and acicular $\alpha$ together. 
(3) The substructures in acicular $\alpha$ are evolved from high-density dislocations or local shear bands, which depend on the orientation relationship between neighboring $\beta$ and $\alpha$. Sequentially, the $\beta$ matrix edges into acicular $\alpha$ along the substructure interface, and then fragments the acicular $\alpha$ gradually. A higher strain rate decreases the deformation time to carry out the fragmentation of acicular $\alpha$, while a higher temperature decreases the dislocation density in the $\beta$ matrix via promoting $\beta$ recovery, which does not benefit the substructure formation and the subsequent fragmentation in acicular $\alpha$. Therefore, the retardation of acicular fragmentation and the resultant decreased flow softening rate can be observed at higher strain rates and temperatures.

Author Contributions: Conceptualization, S.L. and X.Z.; Methodology, K.Z.; Investigation, S.L. and Y.L.; Resources, X.Z.; Data Curation, S.L. and Y.L.; Writing-Original Draft Preparation, S.L.; Writing-Review \& Editing, X.Z. and K.Z.; Project Administration, X.Z.; Funding Acquisition, X.Z.

Funding: This research was funded by the Key R\&D Program of Hunan Province, China grant number 2016 JC2003.

Acknowledgments: The materials used for experiments were supplied by Hunan Goldsky Titanium Industry Technology Co., Ltd., China.

Conflicts of Interest: The authors declare no conflict of interest. The funders had no role in the design of the study; in the collection, analyses, or interpretation of data; in the writing of the manuscript, and in the decision to publish the results.

\section{References}

1. Arrazola, P.J.; Garay, A.; Iriarte, L.M.; Armendia, M.; Marya, S.; LeMaitre, F. Machinability of titanium alloys (Ti6Al4V and Ti555.3). J. Mater. Process. Technol. 2009, 209, 2223-2230. [CrossRef]

2. Warchomicka, F.; Poletti, C.; Stockinger, M. Study of the hot deformation behaviour in Ti-5Al-5Mo-5V-3Cr-1Zr. Mater. Sci. Eng. A 2011, 528, 8277-8285. [CrossRef]

3. Jones, N.G.; Dashwood, R.J.; Dye, D.; Jackson, M. The Flow Behavior and Microstructural Evolution of Ti-5Al-5Mo-5V-3Cr during Subtransus Isothermal Forging. Metall. Mater. Trans. A 2009, 40, 1944-1954. [CrossRef]

4. Boyer, R.R. An overview on the use of titanium in the aerospace industry. Mater. Sci. Eng. A 1996, 213, 103-114. [CrossRef]

5. Nag, S.; Banerjee, R.; Srinivasan, R.; Hwang, J.Y.; Harper, M.; Fraser, H.L. w-Assisted nucleation and growth of $\alpha$ precipitates in the Ti-5Al-5Mo-5V-3Cr-0.5Fe $\beta$ titanium alloy. Acta Mater. 2009, 57, 2135-2147. [CrossRef]

6. Jackson, M.; Jones, N.G.; Dye, D.; Dashwood, R.J. Effect of initial microstructure on plastic flow behavior during isothermal forging of Ti-10V-2Fe-3Al. Mater. Sci. Eng. A 2009, 501, 248-254. [CrossRef]

7. Brian, A.W. Microstructural and Property Relationships in Titanium Alloy Ti-5553; The Ohio State University: Columbus, OH, USA, 2010.

8. Jonas, J.J.; Heritier, B.; Luton, M.J. Anneal hardening and flow softening in beta zirconiumniobium alloys. Metall. Mater. Trans. A 1979, 10,611-620. [CrossRef]

9. Wanjara, P.; Jahazi, M.; Monajati, H.; Yue, S.; Immarigeon, J.-P. Hot working behavior of near- $\alpha$ alloy IMI834. Mater. Sci. Eng. A 2005, 396, 50-60. [CrossRef]

10. Ankem, S.; Shyue, J.G.; Vijayshankar, M.N.; Arsenault, R.J. The effect of volume per cent of phase on the high temperature tensile deformation of two-phase Ti-Mn alloys. Mater. Sci. Eng. A 1989, 111, 51-61. [CrossRef]

11. Philippart, I.; Rack, H.J. High temperature dynamic yielding in metastable Ti-6.8Mo-4.5Fe-1.5Al. Mater. Sci. Eng. A 1998, 243, 196-200. [CrossRef]

12. Ma, X.; Zeng, W.D.; Sun, Y.; Wang, K.X.; Lai, Y.J.; Zhou, Y.G. Modeling constitutive relationship of Ti17 titanium alloy with lamellar starting microstructure. Mater. Sci. Eng. A 2012, 538, 182-189. [CrossRef]

13. Castany, P.; Pettinari-Sturmel, F.; Douin, J.; Coujou, A. In situ transmission electron microscopy deformation of the titanium alloy Ti-6Al-4V: Interface behavior. Mater. Sci. Eng. A 2008, 483-484, 719-722. [CrossRef]

14. Suri, S.; Viswanathan, G.B.; Neeraj, T.; Hou, D.-H.; Mills, M.J. Room temperature deformation and mechanisms of slip transmission in oriented single-colony crystals of an $\alpha / \beta$ titanium alloy. Acta Mater. 1999, 47, 1019-1034. [CrossRef]

15. Guo, Y.; Britton, T.B.; Wilkinson, A.J. Slip band-grain boundary interactions in commercial-purity titanium. Acta Mater. 2014, 76, 1-12. [CrossRef] 
16. Li, L.; Luo, J.; Yan, J.J.; Li, M.Q. Dynamic globularization and restoration mechanism of Ti-5Al-2Sn-2Zr-4Mo-4Cr alloy during isothermal compression. J. Alloys Compd. 2015, 622, 174-183. [CrossRef]

17. Weiss, I.; Froes, F.H.; Eylon, D.; Welsch, G.E. Modification of Alpha Morphology in Ti-6AI-4V by Thermomechanical Processing. Metall. Mater. Trans. A 1986, 17, 1935-1947. [CrossRef]

18. Zherebtsov, S.; Murzinova, M.; Salishchev, G.; Semiatin, S.L. Spheroidization of the lamellar microstructure in Ti-6Al-4V alloy during warm deformation and annealing. Acta Mater. 2011, 59, 4138-4150. [CrossRef]

19. Robertson, D.G.; Mcshane, H.B. Isothermal hot deformation behavior of $(\alpha+\beta)$ titanium alloy Ti-4Al-4Mo-2Sn-0.5Si (IMI 550). Mater. Sci. Technol. 1997, 13, 459-468. [CrossRef]

20. Mironov, S.; Murzinova, M.; Zherebtsov, S.; Salishchev, G.A.; Semiatin, S.L. Microstructure evolution during warm working of Ti-6Al-4V with a colony- $\alpha$ microstructure. Acta Mater. 2009, 57, 2470-2481. [CrossRef]

21. Semiatin, S.L.; Furrer, D.U. Modeling of microstructure evolution during the thermomechanical processing of titanium alloys. In ASM Handbook; Semiatin, S.L., Furrer, D.U., Eds.; Fundamentals of Modeling for Metals Processing; ASM International: Materials Park, OH, USA, 2009; Volume 22.

22. Li, C.; Zhang, X.Y.; Zhou, K.C.; Peng, C.Q. Relationship between lamellar $\alpha$ evolution and flow behavior during isothermal deformation of Ti-5Al-5Mo-5V-1Cr-1Fe near $\beta$ titanium alloy. Mater. Sci. Eng. A 2012, 558, 668-674. [CrossRef]

23. Kim, J.H.; Semiatin, S.L.; Lee, C.S. Constitutive analysis of the high-temperature deformation of Ti-6Al-4V with a transformed microstructure. Acta Mater. 2003, 51, 5613-5626. [CrossRef]

(C) 2018 by the authors. Licensee MDPI, Basel, Switzerland. This article is an open access article distributed under the terms and conditions of the Creative Commons Attribution (CC BY) license (http:/ / creativecommons.org/licenses/by/4.0/). 